\title{
Perbandingan Kandungan Selulosa dan Lignin dari Kayu Acacia crassicarpa dan Acacia mangium
}

\author{
Melysa Putri ${ }^{1}$, Shalsyabila Poeni ${ }^{1}$ \\ ${ }^{1}$ Politeknik ATI Padang, Bungo Pasang-Tabing, Padang, 25171, Indonesia
}

\section{ARTICLE INFORMATION}

Sejarah Artikel:

Diterima Redaksi: 07 Juni 2020

Revisi Akhir: 20 Juni 2020

Diterbitkan Online: 30 Juni 2020

\section{KEYWORDS}

Kayu, Acacia crassicarpa (Ac), Acacia

mangium (Am), Lahan Basah, Lahan kering

\section{CORRESPONDENCE}

Name: Melysa Putri

Email: melysap27@gmail.com

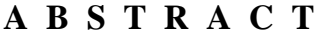

\begin{abstract}
The development of the pulp \& paper industries in Indonesia increase every year. To support the development of industries in Indonesia in order to be able to compete with similar industries from abroad, it is very important to pay attention to the quality of the paper produced. One way to determine the quality of the pulp \& paper is by knowing the chemical composition and area where the wood grows. Important chemical compositions that can support the strength of wood and paper quality include cellulose and lignin. Therefore, this study was conducted to the levels of cellulose and lignin contained in Acacia crassicarpa wood from wetlands and Acacia mangium from dry land which is processed into pulp \& paper with good quality. Determination of cellulose and lignin content in wood was carried out using the gravimetric method. Test results on Acacia crassicarpa wood species from wetlands obtained cellulose content of $55.48 \%$ and lignin $24.13 \%$, while in Acacia mangium wood from dry land obtained cellulose content of $51.46 \%$ and lignin $27.66 \%$. According to The National Indonesian Standards that levels of cellulose in two different fields are obtained according to the standards. So for the results of testing Acacia crassicarpa wood from wetlands has the highest levels of cellulose with low levels of lignin.
\end{abstract}

\section{PENDAHULUAN}

Tingginya kebutuhan dunia terhadap pulp dan kertas ikut mendorong berkembangnya industri pulp dan kertas di Indonesia. Akan tetapi, hal ini belum dapat memenuhi semua kebutuhan dalam negeri dan permintaan ekspor dunia [1]. Berdasarkan data pada tahun 2017, kebutuhan pulp dan kertas dunia mencapai 45 juta $\mathrm{m}^{3}$ atau mengalami kenaikan sebesar 27,5\% jika dibandingkan dengan tahun sebelumnya. Untuk memenuhi kebutuhan tersebut perlu diperhatikan kualitas kertas yang dihasilkan [2].

Kualitas pulp dan kertas tergantung pada bahan baku kayu yang digunakan. Untuk menghasilkan pulp dan kertas yang berkualitas baik harus memperhatikan komposisi kimia dari kayu tersebut [3]. Kayu yang berkualitas bagus mengandung selulosa yang tinggi agar dapat membentuk dinding sel yang akan mempengaruhi kekuatan dari kayu itu sendiri. Semakin tinggi kandungan selulosa pada kayu, maka semakin baik kertas dan pulp (bubur kertas) yang dihasilkan [4]. Selain selulosa, lignin juga merupakan komposisi kimia yang harus diperhatikan. Lignin merupakan komponen kedua terbesar di dalam kayu dan zat yang tidak diinginkan dalam pembuatan pulp dan kertas karena dapat menurunkan kualitas kertas $[5,6]$.

Pentingnya kandungan selulosa dan lignin dalam pembuatan pulp dan kertas mengarahkan peneliti dalam melakukan penelitian ini. Penelitian yang peneliti lakukan bertujuan untuk mengetahui kandungan selulosa dan lignin dari kayu Acacia crassicarpa dan Acacia mangium .

\section{METODOLOGI}

Penelitian ini dilakukan di laboratorium kimia kayu dengan menggunakan erlenmeyer, kondensor, waterbath, kertas saring Whatman-93, alat vaccum pump, kondensor refluks (pendingin balik), oven, hot plate, peralatan gelas lainnya, gelas piala, magnetic stirer, neraca analitik, dan desikator. Sampel yang digunakan pada penelitian ini adalah kayu Acacia crassicarpa dan Acacia mangium yang telah dipotong dan dihaluskan serta diayak dengan menggunakan shaker. Untuk mendukung penelitian ini, peneliti juga menggunakan beberapa pereaksi seperti natrium perborat 
tetrahidrat, asam asetat glacial, $\mathrm{H}_{2} \mathrm{O}_{2} 30 \%, \mathrm{H}_{2} \mathrm{SO}_{4} 72 \%$, etanol $96 \%$, pure water, dan etanol : benzene $1: 2$.

\section{Analisis Selulosa}

Sebanyak 1 gram sampel direfluks dengan campuran 5 gram natrium perborat, $25 \mathrm{~mL}$ asam asetat, dan $25 \mathrm{~mL}$ $\mathrm{H}_{2} \mathrm{O}_{2} 30 \%$ selama 4 jam. Hasil refluks disaring dengan menggunakan kertas saring whatman 93 dan dicuci dengan air panas $2000 \mathrm{~mL}$. Selanjutnya sampel dianalisis dengan menggunakan metode gravimetri [7].

\section{Analisis Lignin}

Sebanyak 1 gram sampel direaksikan dengan $15 \mathrm{~mL}$ $\mathrm{H}_{2} \mathrm{SO}_{4} 72 \%$ yang dimasukkan ke dalam gelas piala yang berisi es batu selama 2 jam. Campuran sampel diekstraksi selama 4 jam, kemudian disaring dengan menggunakan kertas saring Whatman 93. Hasil ekstraksi dicuci dengan menggunakan air panas sebanyak $2000 \mathrm{~mL}$. Hasil ekstraksi dianalisis dengan menggunakan metode gravimetri [7].

\section{HASIL DAN PEMBAHASAN}

Hasil penelitian yang telah dilakukan terhadap kadar selulosa dan lignin dari kayu Acacia crassicarpa dan Acacia mangium dapat diamati pada Gambar 1.

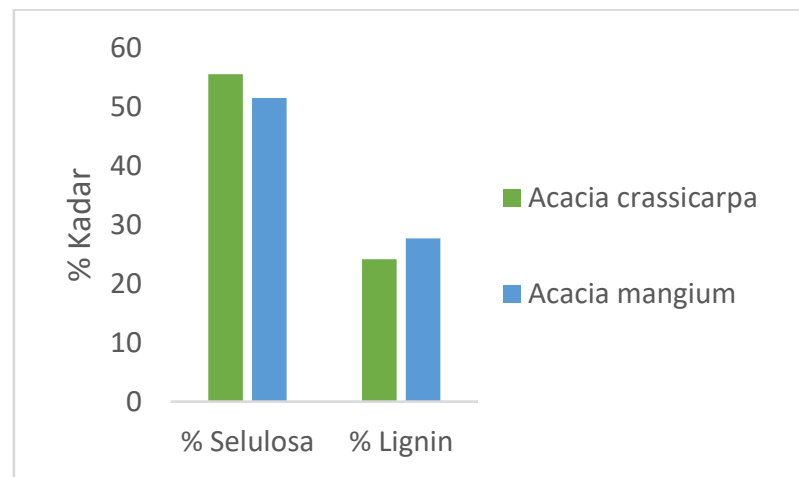

Gambar 1. Perbandingan Kadar Selulosa \& Lignin pada Kayu A. crassicarpa \& A. mangium

Pada gambar 1 dapat dilihat bahwa kandungan selulosa dan lignin pada kayu A. crassicarpa lebih besar dan lebih kecil daripada kayu A. mangium. Kandungan selulosa dan lignin pada A. crassicarpa adalah sebesar $55,48 \%$ dan $24,13 \%$. Sedangkan kandungan selulosa pada kayu A. mangium adalah sebesar $51,46 \%$ dengan kandungan lignin sebesar 27,66\%. Semakin tinggi kandungan selulosa kayu makakandungan ligninnya akan semakin kecil. Perbedaan kandungan selulosa dan lignin pada kedua kayu ini dapat disebabkan karena perbedaan lahan tumbuhnya. A. crassicarpa diketahui tumbuh pada lahan basah sedangkan A. mangium tumbuh pada lahan kering. Kondisi lahan ini mempengaruhi komposisi kimia kayu. Jika dibandingkan dengan lahan kering, lahan basah banyak mengandung unsur hara yang diperlukan dalam proses pertumbuhan kayu. Hal ini dapat disebabkan karena kandungan air dari lahan tumbuh, unsur hara yang terkandung di lahan tumbuh, waktu penanaman dan penebangan kayu, cuaca dan faktor-faktor lainnya [8].

Menurut Standar Nasional Indonesia (SNI) 7274 tahun 2008 tentang komponen kimia pulp diketahui bahwa kandungan selulosa yang terdapat pada pulp yang dihasilkan berkisar antara 45-60\% dengan kandungan lignin sebesar 4-16\%. Jika dibandingkan dengan kandungan selulosa dan kandungan lignin yang telah dianalisis dari kedua sampel kayu tersebut, dapat dikatakan bahwa kedua kayu tersebut dapat diolah menjadi pulp dan kertas walaupun kadar ligninnya melewati batas standar. Hal ini disebabkan karena komponen terpenting dalam pembuatan pulp dan kertas adalah selulosa. Selulosa merupakan komponen yang paling banyak terdapat pada kayu dan zat yang sangat diinginkan guna membentuk dinding-dinding sel kayu yang akan berpengaruh kepada strength atau kekuatan kayu itu sendiri. Semakin tinggi kandungan selulosa kayu, maka akan semakin tinggi pula jumlah pulp yang dihasilkan $[4,5]$.

\section{KESIMPULAN}

Berdasarkan penelitian yang telah dilakukan, dapat disimpulkan bahwa kayu Acacia crassicarpa mengandung selulosa sebesar 55,48\% dan lignin sebesar $24,13 \%$. Sedangkan pada kayu Acacia mangium terdapat selulosa sebesar $51,46 \%$ dan lignin sebesar 27,66\%. Kayu Acacia crassicarpa memiliki kandungan selulosa yang lebih tinggi daripada kayu Acacia mangium. Akan tetapi, kandungan lignin pada Acacia mangium lebih tinggi daripada kandungan lignin pada kayu Acacia crassicarpa.

\section{DAFTAR PUSTAKA}

[1] Sugesty et al.. Potensi Acacia crassicarpa Sebagai Bahan Baku Pulp Kertas Untuk Hutan Tanaman Industri. Jurnal Selulosa, Vol. 5, No.1. Juni 2015, pp. 21-32..

[2] Kementerian Perindustrian Republik Indonesia. Analisis Perkembangan Industri Edisi III. Jakarta Selatan : Pusdatin Kemenperin, 2018.

[3] Muslich, M., \& Rulliaty,S. Ketahanan 45 Jenis Kayu Indonesia Terhadap Kayu Kering dan Rayap Tanah. Jurnal Penelitian Hasil Hutan, 34(1), 2018, pp. 51-59.

[4] Setiadi, Dedi et al,. Analisis Kimia Kayu Pada Tanaman Araucaria cunninghamii Aiton exD.Don 
Untuk Bahan Baku Pulp. Jurnal Pemuliaan Tanaman Hutan Vol. 9, No.1, 2015, pp. 53-60.

[5] Heru S., Wibisono, Jasni \& Wa Ode Muliastuty Arsyad. Komposisi Kimia Dan Keawetan Alami Delapan Jenis Kayu Di Bawah Naungan. Jurnal Penelitian Hasil Hutan Vol. 36 No.1, Bogor : 2018, pp. 59-65.

[6] Bahri, Syamsul. Pembuatan Pulp dari Batang Pisang. Jurnal Teknologi Kimia Unimal 4:2, November 2015, pp. 36-50.

[7] Fengel, D \& Wegener, G. Wood Chemistry, Ultrastructure, Reactions, Sastrohamidjojo, $\mathrm{H}$, (penerjemah): Prawirohatmodjo, S. (penyuting). 1995. Kayu: Kimia, Ultrastruktur, Reaksi-Reaksi. UGM Press. Yogyakarta.

[8] Marsoem, S. N., Prasetyo, F. E., Sudaryono, J., \& Lukman , D.G. Studi Mutu Kayu Jati di Hutan Rakyat Gunung kidul IV. Sifat Mekanika Kayu. Jurnal Ilmu Kehutanan Volume 9 No.2 JuliSeptember 2015. 